\title{
Road mortality of pond-breeding amphibians during spring migrations in the Mazurian Lakeland, NE Poland
}

\author{
Marcin Brzeziński • George Eliava • Michał Żmihorski
}

Received: 28 April 2011 /Revised: 28 December 2011 / Accepted: 9 February 2012 / Published online: 12 April 2012

(C) The Author(s) 2012. This article is published with open access at Springerlink.com

\begin{abstract}
The effects of road traffic mortality on amphibian populations are in many cases hard to estimate and speculate, primarily due to the inaccuracy of the methods employed in studies. We have analyzed amphibian road mortality during two breeding seasons on selected road sections adjoining spawning ponds and have critically reviewed methods used for estimating the impact of road traffic on migrating amphibians. The mortality rates of particular amphibian species differed significantly and varied according to year, site, and traffic volume. The highest mortality was recorded for Bufo bufo and the lowest for Lissotriton vulgaris. Species-specific parameter estimates of mortality, evaluated on a daily basis counts of roadkills, were positively correlated with the mean body mass of the amphibian species. The share of a given species among carcasses found on the road, commonly used in such studies, proved to be an unreliable measure of mortality. We found that nearly $60 \%$ of amphibian roadkill victims had disappeared within $24 \mathrm{~h}$ of exposure, and the number of missing carcasses was inversely related to body mass.
\end{abstract}

Keywords Breeding population · Fencing method · Frogs · Toads $\cdot$ Newts $\cdot$ Roadkill $\cdot$ Carcass persistence

Communicated by A. Aguirre

M. Brzeziński $(\bowtie) \cdot$ G. Eliava

Department of Ecology, University of Warsaw,

ul. Banacha 2,

02-097 Warszawa, Poland

e-mail: marcinb@biol.uw.edu.pl

M. Żmihorski

Museum and Institute of Zoology, Polish Academy of Sciences, ul. Wilcza 64,

00-679 Warszawa, Poland

\section{Introduction}

Among the many factors that negatively affect amphibian populations, human activities are of major importance (Blaustein et al. 1994; Collins and Storfer 2003). Road mortality, which has increased with the expansion of road networks and the growing volume of traffic, is particularly significant (van Gelder 1973; Fahrig et al. 1995; Carr and Fahrig 2001; Cooke and Sparks 2004; Gibbs and Shriver 2005; Andrews et al. 2008; Carvalho and Mira 2011). Amphibians, due to their migratory behavior and rather low velocity, seem to be particularly vulnerable to road traffic compared to other vertebrates (Ashley and Robinson 1996; Glista et al. 2008; Gryz and Krauze 2008). The critical period for amphibians is the breeding season when the number of animals killed on roads increases rapidly (Orłowski et al. 2008). For some amphibian species, the number of roadkill victims is positively correlated with traffic intensity (Fahrig et al. 1995; Mazerolle 2004). However, this is not the case for other species (Mazerolle 2004), and road traffic mortality may depend on the size of the amphibian population and the presence of breeding ponds in the vicinity of roads (Orłowski 2007; Orłowski et al. 2008). The relationships between road networks, traffic intensity and habitat variables on the one hand, and mortality and abundance on the other appear to be very important for understanding and predicting amphibian population dynamics, on both habitat and landscape scales. A few studies have employed such a broad approach (Fahrig et al. 1995; Vos and Chardon 1998; Orłowski et al. 2008), but most usually consider amphibian mortality on a very local scale.

Amphibian road mortality and its consequences for populations have been the subject of studies undertaken not only in various spatio-temporal scales, but also with the use of different methodological tools, which makes it difficult to compare the obtained results and to construct reliable 
syntheses. The review of Elżanowski et al. (2009) is a valuable summary of recent studies, although it highlights the considerable gaps in our knowledge of this subject. The difficulties in comparing various datasets result not only from the different field methods employed by researchers, but also from the imprecise definition of "amphibian road mortality", which often describes only the number of dead individuals (and species composition) recorded on the road. The number of traffic victims found on selected sections of road may provide valuable information about migration routes of particular amphibian species during the breeding season; however, it usually does not relate to the whole breeding population that crosses roadkill hotspots on the way to their spawning sites. As a consequence, the effects of road traffic mortality on amphibian populations, on a habitat or landscape scale, are hard to estimate and speculate (Andrews et al. 2008). For example, mortality rates, which reflect the proportion of traffic victims among the entire sample of animals that cross the road, were found to increase with growing traffic volume, whereas the number of dead amphibians could be the highest at low traffic intensity (Sutherland et al. 2010). Unfortunately, not all authors distinguish between these two measures.

The aims of this study were to analyze amphibian road mortality during spring migrations on selected sections of road in the Mazurian Lakeland (NE Poland) and to critically review methods used for estimating the impact of road traffic on amphibian populations. Following the suggestion of Elżanowski et al. (2009), we supplement some basic results with critical comments to lay a foundation for elaborating standardized methods.

\section{Methods}

Field studies were conducted in the central part of the Mazurian Lakeland, northeastern Poland, in the district of Mikołajki (Fig. 1), from 9 April to 6 May 2006 and from 17 March to 27 April 2007, following the amphibian activity in each year. Three study sites were selected: site A $\left(53.887^{\circ} \mathrm{N}\right.$, $\left.21.656^{\circ} \mathrm{E}\right)$ was placed along the road from Mikołajki to Giżycko (national road no. 643), and sites B $\left(53.859^{\circ} \mathrm{N}\right.$, $\left.21.699^{\circ} \mathrm{E}\right)$ and $\mathrm{C}\left(53.835^{\circ} \mathrm{N}, 21.603^{\circ} \mathrm{E}\right)$ were along the road from Mikołajki to Orzysz (national road no. 16). Both roads are about 6-m wide asphalt roads with two paved lanes, but without paved road verges. Due to the relatively small number of migrating amphibians recorded at site $\mathrm{C}$ in the first year, this site was excluded from the study in 2007. The study sites were placed in the vicinity of amphibian breeding ponds, which were located close to the roads (within $50 \mathrm{~m}$ ). The ponds at sites $\mathrm{A}$ and $\mathrm{B}$ were surrounded by fallows and covered an area of about 1.5 and 2 ha, respectively; whereas, the pond at site $\mathrm{C}$ was located in alder woods (area of about $0.5 \mathrm{ha}$ ). At each site, we constructed $100-\mathrm{m}$ long and $0.5-\mathrm{m}$ high plastic drift fences which extended along the road, forming a partial barrier between the road edge and the pond. Buried water-filled buckets were placed at the end of each fence to function as pitfall traps. The study sites were visited every morning, and all amphibians trapped in the buckets were identified (three frog species: Rana lessonae, Rana ridibunda, and Rana esculenta were not distinguished and were treated as a single group-Rana esculenta complex), counted, weighed, and released into the ponds. The rate of amphibian's falls into buckets per site per day ranged from 0 to 250 . The lowest mean rate was recorded in 2006 at site $\mathrm{C}$ (9.5 animals per day, $\mathrm{SD}=14.7$ ) and the highest in 2006 at site A (47.7 animals per day, $\mathrm{SD}=72.4$ ). All amphibians belonging to the genera Rana and Bufo which weighed less than $6 \mathrm{~g}$ were classified as juveniles. Each day, the 100-m-long road sections parallel to the fences were searched for road traffic victims. At these sections all dead amphibians were identified, counted, and removed from the road. Vehicle passage along the roads was monitored; altogether, the traffic load was recorded during $40 \mathrm{~h}$ in various periods from dawn to dusk. Mean values of traffic intensity were calculated for each site and each year of the study, and these ranged from 34 vehicles/ $\mathrm{h}$ at site $\mathrm{B}$ in 2006 to 116 vehicles/ $\mathrm{h}$ at site $\mathrm{C}$.

In the second year of the study, we attempted to estimate the validity of the method of quantifying roadkills. For this purpose, 76 fresh Rana spp. carcasses of various sizes were placed on the road in the vicinity of site C. All amphibian corpses were placed $1 \mathrm{~m}$ from the asphalt road edge. The position of frogs exposed to the road traffic was marked and the number of carcasses remaining was monitored after 3, 18, and $24 \mathrm{~h}$. During this experiment, vehicle passage was measured in four 1-h periods (excluding night time). The recorded mean traffic intensity was 127 vehicles/h, which was not greatly different from that recorded the previous year. To compare the immigration intensity of amphibians from other directions, in the second year of the study, we constructed three additional, 33-m-long fences along the banks of pond B that did not face the nearby road.

For statistical analysis of the data, we employed generalized linear mixed models (GLMM, Zuur et al. 2009) with Gaussian error distribution and identity link function, implemented in the R program (R Development Core Team 2010) using the lme4 package (Bates and Maechler 2010), in order to take into account variability of the measured parameters in different years, ponds, and species. First, we used GLMM with amphibian species as a fixed categorical factor and year and pond as random categorical factors in a nested design (pond nested in year). With this approach, we were able to assess species-specific estimates of mortality. For this purpose, we used species-specific parameter estimates from the GLMM with $95 \%$ confidence intervals determined by 10,000 Markov chain Monte Carlo permutations. To examine whether the body mass of a given species was associated with its 


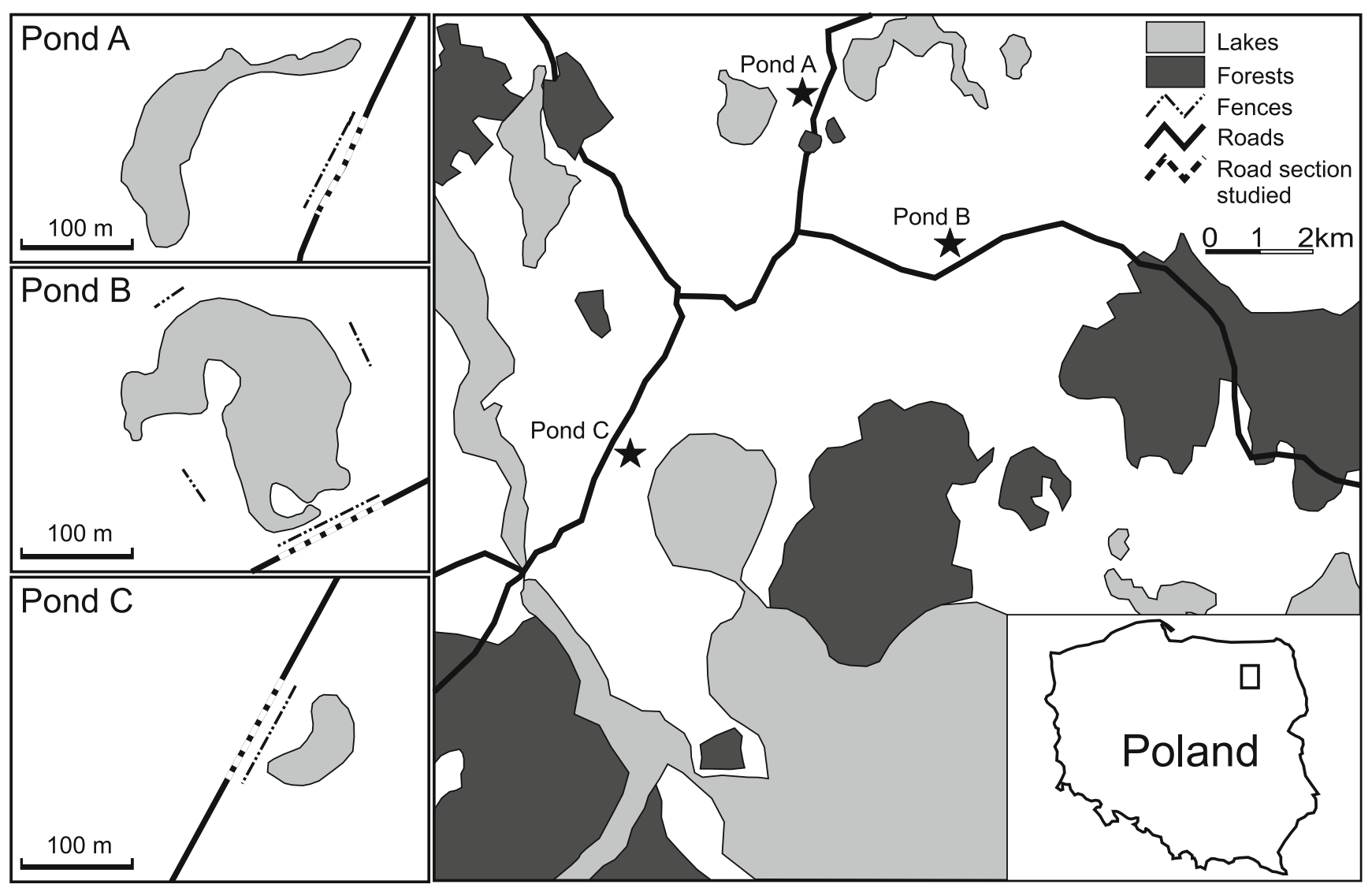

Fig. 1 Study area and study sites

mortality, we introduced body mass of each species measured for each year and pond into the GLMM (the data for pond C were excluded). Finally, data on the share of a given species among carcasses found on the road (independent for the particular pond and year) were introduced into the former GLMM as a covariate. This enabled us to check whether the relative abundance of carcasses of a given amphibian can be used as a reliable explanatory variable for real mortality of this species.

As a second step, we investigated whether the body mass of amphibians affects the survival of their carcasses on the road over a 24-h period. For this purpose, we divided all the carcasses used in the experiment $(n=76)$ into two groups according to their mass: up to $5 \mathrm{~g}(n=39)$ and exceeding $5 \mathrm{~g}$ $(n=37)$. Next, we used Cox survival regression model with body mass category as the covariate and plotted survival functions for the two body mass categories independently. The program SPSS 16.0 was used for the computation.

\section{Results}

Species-specific mortality and relationship to body mass

In total, 5,641 amphibians belonging to at least nine species (at $R$. esculenta complex category more than one species is classified) were trapped: 2,369 individuals that crossed the roads at ponds $\mathrm{A}, \mathrm{B}$, and $\mathrm{C}$ in 2006 and 2,366 at ponds $\mathrm{A}$ and B in 2007. In addition, 906 amphibians which migrated to pond B without crossing the road were trapped in 2007 (not shown in Table 1). The number of amphibians that successfully crossed the roads varied according to the year and site (Table 1). The community structure of the migrating amphibians was also variable. Overall, the smooth newt Lissotriton vulgaris, moor frog Rana arvalis, and common spadefoot Pelobates fuscus were the most numerous adult amphibians trapped on their way to the breeding ponds. Juveniles belonging to Rana spp. were also frequently caught in pitfall traps and comprised about $20 \%$ of all recorded amphibians. The species composition of amphibians trapped at pond B in 2007 differed significantly from the species composition of those migrating to the same pond from other directions $\left(\chi^{2}=75.57 ; d f=8 ; p<0.001\right)$.

In the first and second years of the study, the numbers of recorded road casualties were 161 and 138, respectively. Total mortality of amphibians crossing the roads ranged from $3.4 \%$ at pond $\mathrm{A}$ in 2007 to $11.1 \%$ at pond $\mathrm{C}$ in 2006 . The recorded mortality of adults ranged from $4.3 \%$ to $22.8 \%$ which was significantly higher than that of juveniles (1.4\%). Amphibian mortality was significantly positively correlated with road traffic intensity (linear regression, $R^{2}=0.91 ; F_{1,3}=29.83 ; p=0.012$ ). 
Table 1 Road mortality of amphibians during the spring migrations in 2006 and 2007 at three 100-m-long sections of road in the Mazurian Lakeland

\begin{tabular}{|c|c|c|c|c|c|c|c|c|c|c|c|c|c|c|c|}
\hline \multirow[t]{3}{*}{ Species } & \multicolumn{6}{|c|}{ Pond A } & \multicolumn{6}{|c|}{ Pond B } & \multirow{2}{*}{\multicolumn{3}{|c|}{$\frac{\text { Pond C }}{2006}$}} \\
\hline & \multicolumn{3}{|c|}{2006} & \multicolumn{3}{|c|}{2007} & \multicolumn{3}{|c|}{2006} & \multicolumn{3}{|c|}{2007} & & & \\
\hline & $R$ & $P$ & $M[\%]$ & $R$ & $P$ & $M[\%]$ & $R$ & $P$ & $M[\%]$ & $R$ & $P$ & $M[\%]$ & $R$ & $P$ & $M[\%]$ \\
\hline R. arvalis & 39 & 308 & 11.2 & 14 & 323 & 4.2 & 18 & 90 & 16.7 & 41 & 298 & 12.1 & 9 & 17 & 34.6 \\
\hline R. temporaria & 6 & 58 & 9.4 & 5 & 52 & 8.8 & 6 & 8 & 42.9 & 4 & 10 & 28.6 & 3 & 8 & 27.3 \\
\hline R. esculenta complex & 9 & 53 & 14.5 & 10 & 156 & 6.0 & 13 & 74 & 14.9 & 14 & 73 & 16.1 & 5 & 9 & 35.7 \\
\hline P. fuscus & 2 & 117 & 1.7 & 4 & 80 & 4.8 & 12 & 151 & 7.4 & 22 & 259 & 7.8 & 0 & 0 & 0 \\
\hline B. bombina & 0 & 7 & 0 & 0 & 6 & 0 & 6 & 103 & 5.5 & 3 & 108 & 2.7 & 0 & 0 & 0 \\
\hline B. bufo & 4 & 45 & 8.2 & 4 & 36 & 10.0 & 4 & 25 & 13.8 & 2 & 2 & 50.0 & 4 & 6 & 40.0 \\
\hline B. calamita & 0 & 0 & 0 & 0 & 0 & 0 & 0 & 3 & 0 & 2 & 5 & 28.6 & 0 & 0 & 0 \\
\hline B. viridis & 0 & 0 & 0 & 0 & 0 & 0 & 0 & 9 & 0 & 4 & 11 & 26.7 & 0 & 0 & 0 \\
\hline L. vulgaris & 10 & 421 & 2.3 & 2 & 208 & 1.0 & 3 & 119 & 2.5 & 6 & 329 & 1.8 & 0 & 31 & 0,0 \\
\hline Adults - subtotal & 70 & 1,009 & 6.5 & 39 & 861 & 4.3 & 62 & 582 & 9.6 & 98 & 1,095 & 8.2 & 21 & 71 & 22.8 \\
\hline Rana sp. juv. & 4 & 334 & 1.2 & 1 & 246 & 0.4 & 4 & 272 & 1.4 & 0 & 138 & 0 & 0 & 94 & 0 \\
\hline Bufo sp. juv. & 0 & 0 & 0 & 0 & 26 & 0 & 0 & 4 & 0 & 0 & 0 & 0 & 0 & 3 & 0 \\
\hline Juveniles - subtotal & 4 & 334 & 1.2 & 1 & 272 & 0.4 & 4 & 276 & 1.4 & 0 & 138 & 0 & 0 & 97 & 0 \\
\hline Total & 74 & 1,343 & 5.2 & 40 & 1,133 & 3.4 & 66 & 858 & 7.1 & 98 & 1,233 & 7.4 & 21 & 168 & 11.1 \\
\hline
\end{tabular}

$R$ number of road traffic victims, $P$ number of amphibians captured in pitfall traps, $M$ mortality $(R / R+P \times 100 \%)$

Differences in the mortality pattern of particular amphibian species were recorded (Table 1), but the mortality rates varied according to the year and site. At pond A, the overall mortality rates over 2 years were the highest for Rana temporaria (9.1\%), Bufo bufo (9.0\%), and R. esculenta complex $(8.3 \%)$. We did not find any killed Bombina bombina, but this species occurred in small numbers at this site. Pooled data from pond $\mathrm{B}$ showed that $R$. temporaria suffered the highest mortality among all amphibians (35.7\%), followed by three species of toad (16.7-20.0\%) and $R$. esculenta complex (17.5\%). The mortality of B. bombina was relatively low $(4.1 \%)$, despite the fact that this was a common migrant at this site. At both ponds $\mathrm{A}$ and $\mathrm{B}$, we recorded very low numbers of dead newts and just nine killed Rana spp. juveniles. Most of the road traffic casualties at pond $\mathrm{C}$ were $B$. bufo, although due to the relatively small sample size, these data are less reliable.

The adult moor frog $R$. arvalis, despite relatively low mortality rates compared to other species, was the most numerous road traffic victim. At all sites, their proportion among all dead individuals was significantly higher than among individuals that successfully crossed the roads. A similar pattern was found for $R$. esculenta complex and $R$. temporaria, whereas that for juvenile amphibians and newts was quite the opposite. Common newts were found in large numbers in pitfall traps at each of the sites $(1,108$ in total, over $20 \%$ of all amphibians), but the number of recorded newt carcasses was very low. In total we found 21 dead newts: 12 at pond $\mathrm{A}, 9$ at pond $\mathrm{B}$, and none at pond $\mathrm{C}$.

According to the GLMM, taking random variation between the years and ponds into account, mortality differed significantly between particular amphibian species. The highest mortality was noted for $B$. bufo and the lowest for L. vulgaris, and confidence intervals for the estimates did not overlap between the two species (Fig. 2).

Species-specific parameter estimates of mortality were positively correlated with the mean body mass of each species (linear regression, estimate $=0.59 ; R^{2}=0.48 ; F_{1,7}=$ $6.50 ; p=0.038$; Fig. 3). However, data on body mass introduced into the GLMM, together with species used as a fixed factor, were not significant. Species-specific mortality estimates obtained from the model taking body mass into account were highly positively correlated with the estimates obtained from the former GLMM presented in Fig. 2 (Pearson correlation, $r=0.94 ; p<0.001$ ).

Number of traffic victims as an estimator of amphibian road mortality

The share of a given species among carcasses found on the road was a rather weak and insignificant predictor of its mortality in a given pond and year (Fig. 4). The GLMM using year, pond, and species as random categorical factors showed that the share of a particular species in roadkill 


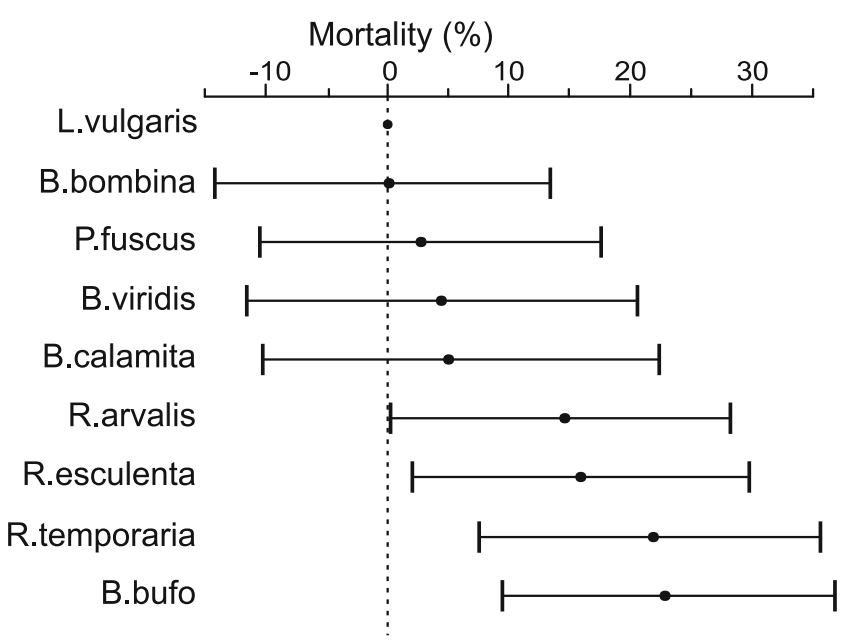

Fig. 2 Species-specific estimates of mortality (expressed in percent) from the generalized linear mixed model (filled dots) and 95\% confidence intervals determined by 10,000 Markov chain Monte Carlo permutations (whiskers). The mortality for L. vulgaris was used as the reference category in parameter estimates in the GLMM, and therefore its parameter of mortality is set to zero

samples did not correlate significantly with the mortality of this species (estimate $=0.26 \pm 0.287 \mathrm{SE} ; t=0.89 ; p>0.05$ ).

Experimental survival of amphibian carcasses on the road

Of the 76 amphibian carcasses placed on the road near site $\mathrm{C}$, just 31 remained after $24 \mathrm{~h}(40.8 \%)$. The survival rate differed significantly between large and small individuals

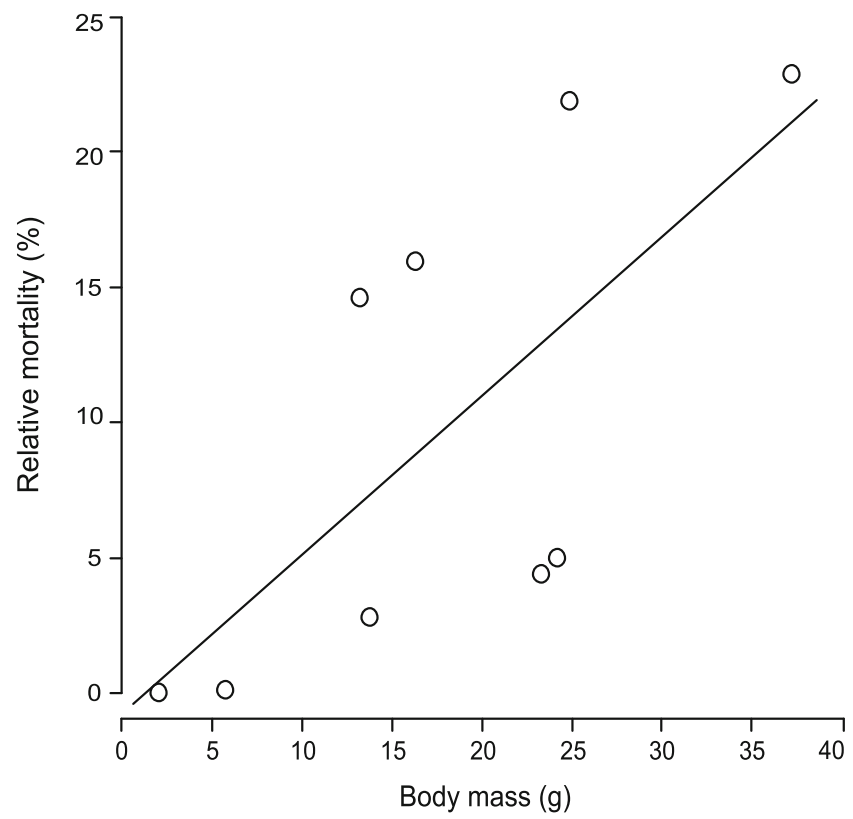

Fig. 3 Relationship between species-specific mean body mass and estimated mortality from the generalized linear mixed model presented in Fig. 2

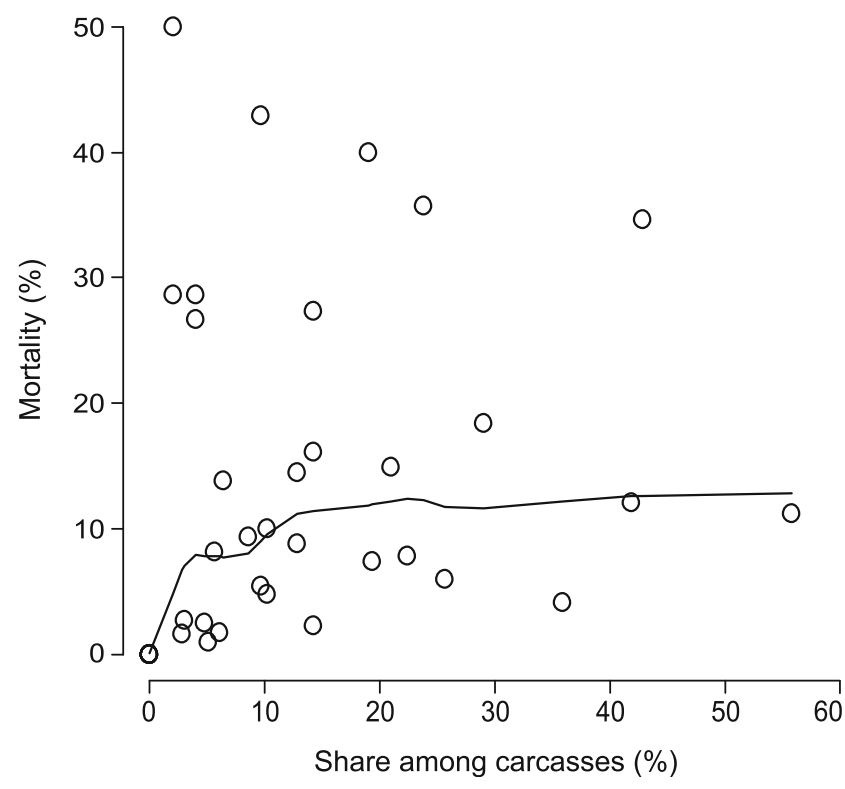

Fig. 4 The relationship between the share of a given species in carcasses found on the road and mortality of this species. LOESS smoother was added to aid visual interpretation

(Fig. 5). Only $20.5 \%$ of the small-bodied carcasses survived until the end of the experiment, whereas the proportion of large-bodied carcasses remaining was three times higher (62\%). Cox survival regression model revealed that the body mass category significantly contributed to the survival of amphibian carcasses on the road (estimate $=0.48( \pm 0.163 \mathrm{SE})$, Wald $=8.85, d f=1, p=0.003$ ).

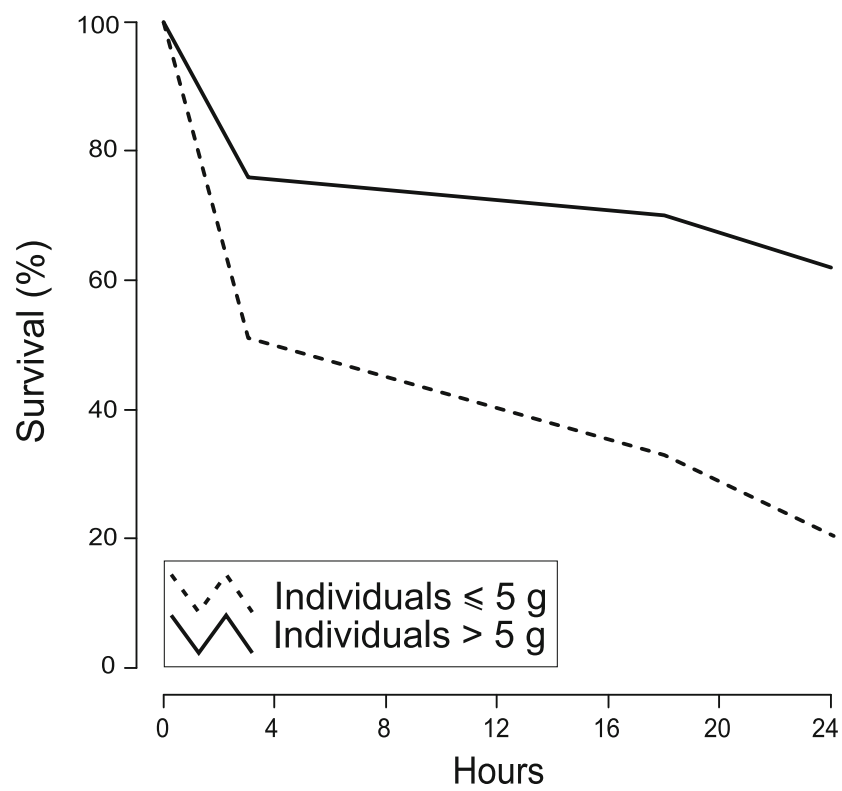

Fig. 5 Experimental survival (in percent) of large-bodied amphibian individuals (body mass $>5 \mathrm{~g}$ ) and small-bodied individuals (body mass $\leq 5 \mathrm{~g}$ ) on the road over a 24 -h period 


\section{Discussion}

Studies of amphibian road mortality have to be based as far as possible on reliable data, which should, where necessary, be modified by suitable corrections. The more estimates used in relation to the number of road victims, the successful road transients or the whole breeding population, the greater the inaccuracy of the obtained figures for amphibian mortality (Elżanowski et al. 2009). To achieve information on amphibian mortality rate, we collected data on the numbers and species composition of amphibian migrants, we counted the number of traffic victims, and finally we estimated experimentally the bias in mortality rate resulting from the differences in body mass of the studied amphibian species. The trapping method enabled rather unbiased counts of animals that successfully crossed the roads in the study sites. However, controls of the number of traffic victims, conducted once a day, were insufficient for precise estimation of the roadkills. The frequency of these controls was the main limitation that underestimated the number of amphibians killed on the roads.

The main factors affecting amphibian road mortality are traffic intensity, daily activity, and velocity of the species (Hels and Buchwald 2001). However, models of the probability of being killed for individuals of different species, elaborated by Hels and Buchwald (2001), show that where the traffic intensity is very high $(>625$ vehicles/h), the velocity of amphibians does not influence their chance of survival while crossing the road, and the probability of getting killed is close to 1 . In our study areas, the traffic intensity was much lower than the calculated critical value - it ranged from 34 to 116 vehicles/h - thus the recorded mortality rates were relatively low and the majority of individuals of all species successfully crossed the roads on their way to the breeding ponds. It is obvious that typical nocturnal species with a higher velocity are less affected by road traffic than slow moving and more diurnal species (Hels and Buchwald 2001). For example, these authors estimated that the probability of being killed was lower for the common spadefoot $P$. fuscus due to its nocturnal activity and the low traffic intensity at night. We also found that the mortality of this species was relatively low. Among all amphibians recorded in Mazurian Lakeland study sites, only P. fuscus and Bufo viridis are strictly nocturnal during their spring migrations, whereas all other species migrate at night as well as in the daytime, according to the weather conditions (Juszczyk 1987).

The behavioral differences between species often seem to be insufficient to explain the differences in recorded mortality rates, and this is because of the significant methodological biases which are difficult to avoid while studying amphibian road mortality. The death rates of animals crossing roads are usually underestimated because their corpses are mechanically damaged by passing vehicles and are often quickly removed by scavengers (Slater 2002; Antworth et al. 2005; Najbar et al. 2006; Santos et al. 2011). In our study, the estimation of the number of amphibians killed by vehicles, despite the collection of traffic victims every day, was biased. Roadkills were underestimated, and according to our experiment, nearly $60 \%$ of amphibian carcasses were missing $24 \mathrm{~h}$ after their exposure. Most importantly, the number of missing dead individuals was negatively related to their body mass. This corresponded to the fact that in our studies, the recorded mortality of species with high mean body mass was higher than that of small species. These observations complicate comparisons of the mortality rates of particular amphibian species. Overestimation of the abundance of large amphibian species from road transect counts has previously been highlighted (Puky 2001). Furthermore, Hels and Buchwald (2001) reported a higher probability of finding $P$. fuscus and B. bufo than other anurans, but related this to their tough skin and unpalatability rather than their size. Nevertheless, this strong size-recordability relationship may have serious consequences for the final outcome of studies aimed at species-specific mortality estimation (Santos et al. 2011).

The frequency of road victims counts seems to be another methodological problem. In the majority of studies, the recorded data were based on counts made less often than once a day (Fahrig et al. 1995; Orłowski 2007; Santos et al. 2007; Gryz and Krauze 2008; Hartel et al. 2009, reviewed by Elżanowski et al. 2009). Several studies used various frequencies of counts in particular study areas (e.g., Orłowski et al. 2008; Elżanowski et al. 2009), and only a few counted roadkill victims once (van Gelder 1973; Hels and Buchwald 2001; Santos et al. 2011) or several times per day (e.g. Najbar et al. 2006). Moreover, counts were often made by car (or initially by car and then on foot during peak migration periods; Puky 2001; Orłowski 2007; Santos et al. 2007; Hartel et al. 2009), which even at low speed, is less precise than walking along the road and increases the proportion of missed animals, particularly small species (Langen et al. 2007; Orłowski et al. 2008; Elżanowski et al. 2009). Correction factors, which take into account differences in amphibian body mass and the probability of finding their corpses, are necessary for more accurate mortality rate estimates (see Hels and Buchwald 2001), but these are not standard values and should be calculated according to the traffic intensity and the frequency of road victims counts in a particular study area. Thus, these correction factors should not be adopted from previous studies, nor should they be used universally, as suggested by Elżanowski et al. (2009).

The different methodological approaches used for the interpretation of mortality and in field methods employed by researchers make the comparison of results difficult and perhaps impossible. For example, toads and common frogs are considered to suffer the highest road mortality of all 
European amphibians (Orłowski et al. 2008; Elżanowski et al. 2009); however, in some regions of Southern Europe, besides toads there are also other species, such as fire salamander Salamandra salamandra and Iberian spadefoot toad Pelobates cultripes (Carvalho and Mira 2011). Indeed, in the Mazurian Lakeland, the mortality rates of toads and common frogs were the highest if we related the number of dead animals found to the number of individuals that successfully crossed the road (this approach is not common, see "Discussion" section below). However, in this study, the moor frog and the common spadefoot were more numerous victims than toads and common frogs. The conclusion that moor frog populations are less affected by road mortality than those of the common frog (Elżanowski et al. 2009) might be valid for some areas, but it may also be biased by the higher probability of finding common frog carcasses due to their significantly higher body mass (on average they are twice as large as moor frogs $-R$. temporaria mean body mass $=25.2 \mathrm{~g}, \mathrm{SD}=9.8 ; R$. arvalis mean body mass $=13.2 \mathrm{~g}$, $\mathrm{SD}=3.4$ - this study, calculated for both years for sites A and B). In the present study, we also recorded relatively high mortality rates for green frogs ( $R$. esculenta class), which contrasts with the lower values determined in previous studies (review in Elżanowski et al. 2009). The predominance of the common toad among all amphibian roadkills may have some ecological explanations (see Orłowski et al. 2008), but we propose that the large body mass of this species increases the probability of finding dead animals and thus overestimates its proportion among traffic victims.

The variation in the results obtained by separate studies may also be due to the fact that "amphibian road mortality" is interpreted in different ways. Mortality is a measure of the number of deaths in a population and can be determined by observing how many individuals die within a certain time and space (see Krebs 1985, Mackenzie et al. 2001). The term mortality should not be used for describing species share of road kills, which is the proportion of dead amphibians of different species with respect to the total number of amphibians found dead. Also giving the number of dead animals per time and per road section without relation to the number of successful migrants produces misleading information. Our analysis showed that the relative abundance of carcasses of a given amphibian species is not a reliable estimator of the mortality of that species. Therefore, estimates based on victim counts have weak relationships with mortality at the population level. The mortality of roadcrossing migrants must be related to the entire sample of individuals that crossed the road on the studied section. Another approach is to compare the mortality to the whole spawning population in a certain pond or area (Hels and Buchwald 2001; Elżanowski et al. 2009). Thus, road traffic mortality, even if defined properly, can be expressed in two ways: as roadkills/road transients on a given section of road or as roadkills/number of spawners in a given pond. As has been stated by Elżanowski et al. (2009), it is obvious that in most cases, only a fraction of a spawning population crosses a surveyed section of road on their way to the breeding pond. Therefore, the estimated road mortality relates only to this fraction and is higher than mortality related to the entire breeding population. Despite the fact that overestimations of the whole-population mortality calculated as the ratio of the number of roadkill victims/number of spawners may be compensated by underestimations resulting from the low recordability of killed animals (Elżanowski et al. 2009), this does not get us closer to more reliable estimates because the scale of this compensation is usually unknown. In the present study, the composition and abundance of amphibian species that migrated to pond B across the road and from other directions were significantly different. Raw extrapolation of the pooled number of amphibians (which denoted $2,139)$ from fences at pond $B(100 \mathrm{~m}+3 \times 33 \mathrm{~m}$ of fence $)$ to the whole perimeter of the pond $(514 \mathrm{~m})$ indicates total number of ca. 5,500 individuals migrating to the breeding site.

The fencing method has not been widely used for estimating the numbers of migrating amphibians because it is laborious, and other methods seem to be more popular for quantifying breeding populations (e.g., Fahrig et al. 1995; Hartel et al. 2009). The fencing is possible only for very short stretches of road and is practically not feasible in studies of mortality of amphibians across the landscape scale. However, we believe that the road fencing method is a good way of estimating the number of individuals that successfully cross the road, and it is not necessary to construct very long fences to obtain reliable results if the section of road is chosen carefully. With the fencing method, all individuals, both diurnal and nocturnal, can be counted. The continuous counting of animals that cross the road (e.g. van Gelder 1973; Fahrig et al. 1995; Puky 2001; Hartel et al. 2009) is imprecise because it is usually done over very short time intervals and often only during the night. Such a method permits estimation of the relative abundance of amphibian species; however, it cannot be used for estimating total numbers. A good example highlighting the inadequacy of such counts can be found in the report of Najbar et al. (2006). These authors compared the number of amphibians collected on the road to the number of animals captured in pitfall traps (fencing method) on the same section of road. The number of captured animals was nearly sevenfold higher than the number collected on the road. The fencing method can also be used to estimate the total number of spawners migrating to a given pond (Hels and Buchwald 2001), but this is considerably more laborious, as much longer fences must be constructed, which should encircle the whole breeding site.

Due to the numerous methodological problems, estimating road mortality rates for many animal species remains extremely difficult. The accuracy of road mortality monitoring surveys can be improved by well planned and long-term 
studies (see Santos et al. 2011). Some additional solutions may be found by constructing models which estimate the impact of road traffic on wildlife according to the road network, traffic volumes, and speeds (Hels and Buchwald 2001; Jaarsma et al. 2006). However, despite these valuable efforts, developed and improved field studies, such as that described in this work, are still required to collect additional data which may be used to produce models that can give more precise estimates.

\section{Conclusions}

1. Estimated mortality rates of particular amphibian species are not only a function of their velocity, daily activity, and other biological features, they are also strongly related to their size - the larger the amphibian, the higher the apparent mortality. However, this relation is presumably less pronounced if study design provides more frequent roadkill counts.

2. The true mortality must be estimated in relation to the total number of amphibians of particular species that attempt to cross the road in a given section and not just by the proportion of dead animals found by researcher. The most precise method of estimating amphibian numbers seems to be fences and pitfall traps installed between the road edge and the breeding pond.

3. Detection of amphibians killed on the road must be done in short time intervals (a few times per day if possible); otherwise, the majority of road traffic victims are not found. Detecting road victims by car and with long time intervals are (in our opinion) useless for estimating true mortality rates.

4. Correction factors may be used for estimating amphibian mortality, but they should be related to local traffic intensity, the frequency of roadkill counts, and possibly weather events (rain and temperature) during the monitoring programs.

Open Access This article is distributed under the terms of the Creative Commons Attribution License which permits any use, distribution, and reproduction in any medium, provided the original author(s) and the source are credited.

\section{References}

Andrews KM, Gibbons JW, Jochimsen DM (2008) Ecological effects of roads on amphibians and reptiles: a literature review. In: Mitchell JC, Jung Brown RE, Bartholomew B (eds) Urban herpetology. Society for the Study of Amphibians and Reptiles, Salt Lake City, pp 121-143
Antworth RL, Pike DA, Stevens EE (2005) Hit and run. Effects of scavenging on estimates of roadkilled vertebrates. Southeast Nat 4:647-656

Ashley PE, Robinson JT (1996) Road mortality of amphibians, reptiles and other wildlife on the Long Point Causeway, Lake Erie, Ontario. Can Field Natur 110:403-412

Bates D, Maechler M (2010) lme4: linear mixed-effects models using S4 classes. R package version 0.999375-37. Available at: http:// CRAN.R-project.org/package $=1 \mathrm{me} 4$

Blaustein AR, Wake DB, Sousa WP (1994) Amphibian declines: judging stability, persistence, and susceptibility of populations to local and global extinctions. Conserv Biol 8:60-71

Carr LW, Fahrig L (2001) Effect of road traffic on two amphibian species of differing vagility. Conserv Biol 15:1071-1078

Carvalho F, Mira A (2011) Comparing annual vertebrate road kills over two time periods, 9 years apart: a case study in Mediterranean farmland. Eur J Wild Res 57:157-174

Collins JP, Storfer A (2003) Global amphibian declines: sorting the hypotheses. Diversity Distrib 9:89-98

Cooke AS, Sparks TH (2004) Population declines of Common Toads (Bufo bufo): the contribution of road traffic and monitoring value of casualty counts. Herpetol Bull 88:13-26

R Development Core Team (2010) R: a language and environment for statistical computing. R Foundation for Statistical Computing, Vienna, Austria. ISBN 3-900051-07-0, URL: http://www.Rproject.org/

Elżanowski A, Ciesiołkiewicz J, Kaczor M, Radwańska J, Urban R (2009) Amphibian road mortality in Europe: a meta-analysis with new data from Poland. Eur J Wildl Res 55:33-43

Fahrig L, Pedlar JH, Pope SE, Taylor PD, Wegner JF (1995) Effect of road traffic on amphibian density. Biol Conserv 73:177-182

Gibbs JP, Shriver WG (2005) Can road mortality limit populations of pool-breeding amphibians? Wetlands Ecol Manage 13:281-289

Glista DJ, DeVault TL, DeWoody JA (2008) Vertebrate road mortality predominantly impacts amphibians. Herpetological Conserv Biol 3:77-87

Gryz J, Krauze D (2008) Mortality of vertebrates on a road crossing the Biebrza Valley (NE Poland). Eur J Wildl Res 54:709-714

Hartel T, Moga CI, Öllerer K, Puky M (2009) Spatial and temporal distribution of amphibian road mortality with a Rana dalmatina and Bufo bufo predominance along the middle section of the Târnava Mare Basin, Romania. North-Western J Zool 5:130-141

Hels T, Buchwald E (2001) The effect of road kills on amphibian populations. Biol Conserv 99:331-340

Jaarsma CF, van Langevelde F, Botma H (2006) Flattened fauna and mitigation: traffic victims related to road, traffic, vehicle, and species characteristics. Transport Res Part D 11:264-276

Juszczyk W (1987) Płazy i gady krajowe. 2nd edn, PWN Warsaw. [in Polish]

Krebs CJ (1985) Ecology. The experimental analysis of distribution and abundance. 3rd edn. Harper \& Row, New York

Langen TA, Machniak A, Crowe E, Mangan C, Marker DF, Liddle N, Roden B (2007) Methodologies for surveying herpetofauna mortality on rural highways. J Wildl Manage 71:1361-1368

Mackenzie A, Ball AS, Virdee SR (2001) Ecology, 2nd edn. BIOS Scientific, Oxford

Mazerolle MJ (2004) Amphibian road mortality in response to nightly variations in traffic intensity. Herpetologica 60:45-53

Najbar B, Najbar A, Maruchniak-Pasiuk M, Szuszkiewicz E (2006) Mortality of amphibians on a road in the Zielona Góra town region in the years 2003-2004. Chrońmy Przyrodę Ojczysta 62:64-71 [in Polish with English summary]

Orłowski G (2007) Spatial distribution and seasonal pattern in road mortality of the common toad Bufo bufo in an agricultural landscape of south-western Poland. Amphibia-Reptilia 28:25-31 
Orłowski G, Ciesiołkiewicz J, Kaczor M, Radwańska J, Żywicka A (2008) Species composition and habitat correlates of amphibian roadkills in different landscapes of south-western Poland. Pol J Ecol 56:659-671

Puky M (2001) Herpetological methods: I On the use of road transect method in surveying amphibians with examples from different zoogeographical regions of Hungary. Opusc Zool Budapest 23:75-81

Santos X, Llorente GA, Montori A, Carretero MA, Franch M, Garriga N, Richter-Boix A (2007) Evaluating factors affecting amphibian mortality on roads: the case of the common toad Bufo bufo, near a breeding place. Anim Biodivers Conserv 30:97-104

Santos SM, Carvalho F, Mira A (2011) How long do the dead survive on the road? Carcass persistence probability and implications for road-kill monitoring surveys. PLoS One 6(9):e25383. doi:10.1371/journal.pone.0025383
Slater FM (2002) An assessment of wildlife road casualties - the potential discrepancy between numbers counted and numbers killed. Web Ecology 3:33-42

Sutherland RW, Dunning PR, Baker WM (2010) Amphibian encounter rates on roads with different amounts of traffic and urbanization. Conserv Biol 24:1626-1635

van Gelder JJ (1973) A quantitative approach to the mortality resulting from traffic in a population of Bufo bufo L. Oecologia 13:93-95

Vos CC, Chardon JP (1998) Effect of habitat fragmentation and road density on the distribution pattern of the moor frog Rana arvalis. $\mathrm{J}$ Appl Ecol 35:44-56

Zuur AF, Ieno EN, Walker NJ, Saveliev AA, Smith GM (2009) Mixed effects models and extensions in ecology with R. Springer, New York 